\title{
Accidental Intra-Arterial Injection during Test Dose of Injection of Benzyl Penicillin: Complications and Management- A Case Report
}

\author{
Amarjit Singh*, Kuldip Singh Sidhu, Shivaji Rai \\ Department of Cardio-Thoracic and Vascular Surgery, Government Medical College, Amritsar, India \\ Email: ${ }^{*}$ amariitdr@gmail.com
}

Received 15 February 2015; accepted 8 June 2015; published 11 June 2015

Copyright (C) 2015 by authors and Scientific Research Publishing Inc.

This work is licensed under the Creative Commons Attribution International License (CC BY). http://creativecommons.org/licenses/by/4.0/

\section{(c) (7) Open Access}

\begin{abstract}
An 18 years old female patient was given a test dose of Benzyl penicillin in the Antecubital Area on the right forearm by a staff nurse of the department. After the injection, the patient complained of severe pain in the right forearm distal to the injection site. This was followed by blanching of the right forearm and hand. She was immediately heparinised followed by other symptomatic treatments. After 12 hours, a bluish discoloration developed on the hand, both on dorsal and palmar aspect, sparing the thumb. This recovered with medication, except the late development of dry gangrene of the tip of distal phalanx of the little finger which got shrivelled later on. Color Doppler flow study, echocardiography, and CT angiography of the right upper limb were done. Understanding of the pathogenesis and prompt action can help in saving a limb. Education of the medical professionals involved in administering injection is necessary so that they become aware of abnormal course or anomalous anatomy of vessels of upper limb. This can help to prevent the complications.
\end{abstract}

\section{Keywords}

Intra-Arterial Injection, Gangrene, Anomalous Anatomy

\section{Introduction}

Accidental intra-arterial injection of medication may lead to severe morbidity [1] [2]. It has been reported to ${ }^{*}$ Corresponding author.

How to cite this paper: Singh, A., Sidhu, K.S. and Rai, S. (2015) Accidental Intra-Arterial Injection during Test Dose of Injection of Benzyl Penicillin: Complications and Management-A Case Report. Case Reports in Clinical Medicine, 4, 222-226. http://dx.doi.org/10.4236/crcm.2015.46043 
occur with many drugs, commonly with barbiturates, thiopental sodium, narcotics, tranquillizers, long acting penicillin and recently with analgesic like Diclofenac sodium [1] [3]-[6], when given inadvertently by intraarterial route. Intra-arterial cannulation can occur in any age group but IA cannulation with penicillin [5] [7] [8] is common in babies. Nowadays, it is increasingly seen in IV drug abusers [3] [9]. It occurs more commonly in antecubital fossa [1] [6] where branches of radial and brachial artery are more superficial or there may be anomalies of these vessels [1] [6] [10]. Wrong site selected for testing, and wrong technique on the part of ancillary staff all may lead to accidental cannulation of an artery. This may result in serious sequeale like severe pain, pallor, motor dysfunction, compartment syndrome, gangrene of distal part and rarely limb loss [1] [2] [10]. It is a medical emergency. With timely diagnosis and early intervention, limb perfusion can be restored [3] [10] and severity of morbidity can be reduced to minimum by Initiating anticoagulation, instituting symptomatic relief and specific rehabilitation [1]-[3] [6]. The paramedical staff who are involved in the administration of injections should be well trained and be well aware of complications resulting from accidental intra-arterial cannulation.

\section{Case Report}

A young female 18 years old who had undergone triple valve replacement about a month back came for follow up and chemoprophylaxis. As a routine, prior to administration, a test dose of Injection Benzyl Penicillin $0.2 \mathrm{ml}$ was given by the qualified trained staff nurse on the right forearm. After a few minutes, the patient developed severe pain in the forearm. Within a short time the whole right forearm got blanched (turned pale white) and paresis of the forearm occurred along with wrist drop. Patient also complained of numbness and burning sensation in hand and forearm.

On examination, the limb was found to be cold and clammy with impalpable ulnar and radial pulses. Immediately patient was given injection daltaparin $5000 \mathrm{iu} \mathrm{s/c} \mathrm{(LMWH),} \mathrm{inj} \mathrm{hydrocortisone} 100 \mathrm{mg}$ iv, Inj Tramadol Hydrochloride $25 \mathrm{mg}$ im and $25 \mathrm{mg}$ in drip. The part was kept warm by covering it with a blanket. The patient was already taking oral anticoagulants (Tab Nicounalome $3 \mathrm{mg}$,) and antiplatelets (Tab Acetylsalicylic acid 150 mg, and Tab clopidrogel).

After half an hour the blanching started disappearing and dusky greyish mottling appeared at places on hand and forearm. The patient also complained of weakness in forearm and inability to extend the wrist joint. The patient was kept under observation. Pain started decreasing. The radial and ulnar pulses appeared within a few minutes probably due to release of arterial spasm. After 12 hour bluish discoloration of the fingers of hand sparing the thumb developed (Figure 1). The patient was advised for colour Doppler flow study of right upper limb and echocardiography as patient was a case of triple valve replacement, which proved to be normal. Afterward she was advised CT Angiography of Right upper limb which also revealed normal study of arteries.

Her complete blood count was carried out.

Hb: 11.8 gm\%, TLC: 8100/cmm, DLC: Neutrophil: 60\%, lymphocytes: 31\%, monocyte: 03, eosinophil: 03\%.

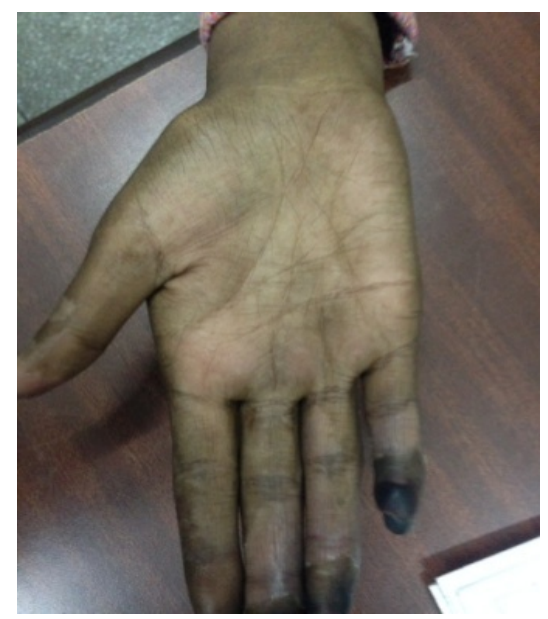

Figure 1. Blue discoloration with gangrene little finger. 
Packed cell volume: 36\%. Prothrombin time (PT): 18 sec control PT: 14 sec, PTI: 77.7 sec as the patient was already on Anticoagulants due valve replacement.

Later on the patient was treated as an OPD case. On follow up, she was found to have regained full function of the forearm and wrist. The patient developed blackening of the skin of distal phalanges of all the fingers and complete gangrene of the tip of the distal phalanx of the little finger (Figure 2). After 2 months the tip of distal phalanx got shrivelled off sparing the nail bed and the necrosed skin of the hand got peeled off, and replaced by normal skin (Figure 3).

\section{Discussion}

Most cases of unintentional cannulation in the upper limb have been reported to occur while IV administration of medication [1]-[11] either itragenically or self administration [1] [3] [10] as in cases of IV drug abusers [3] [9] [11]. Estimated by some authors incidence of this complication is between 1:3500 to 1:5600 [1] [3].

J. M. William et al. described that accidental intra-arterial injection of penicillin is most common in babies [8]. Freudenthal in 1924 suggested the mechanism behind it. The viscous penicillin solutions are difficult to inject

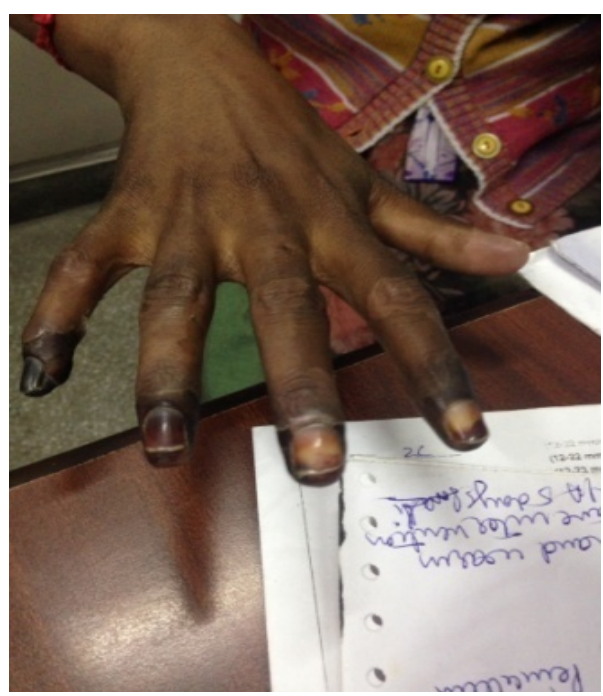

Figure 2. Gangrene distal phalanx little finger right hand.

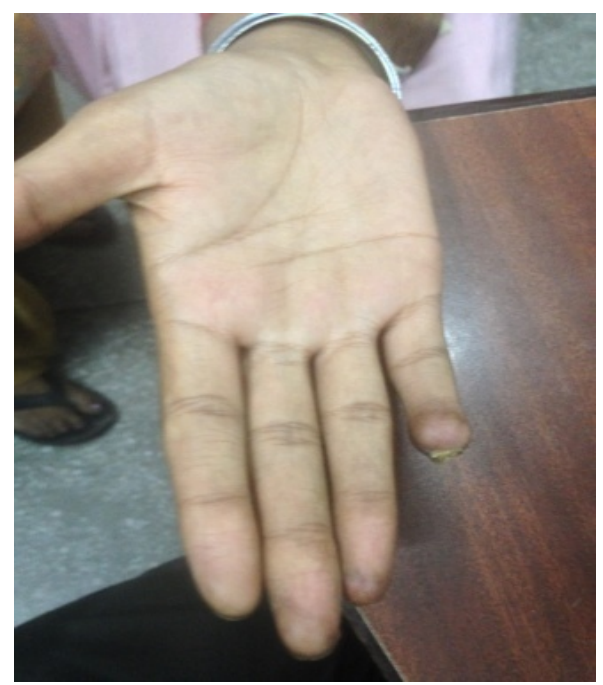

Figure 3. After 2 month tip of distal phalanx got shrivelled off. 
and so are given forcefully (Gorden and Dove, 1972). Aspirations no guarantee that tip of needle is not in artery (Knowles, 1966). During administration, with moment of part where drug is injected or force applied, needle may enter into artery. When drug is injected forcefully retrograde flow into vessels (artery) occur [8].

Accidental intra-arterial injection occur most commonly in antecubital fossa [1] [6], where branches of ulnar, radial and brachial arteries are more superficial and easily entered [1] [3]. A pre-existing vascular [1]-[3] anomaly is a risk factor commonly overlooked by health care professionals [3] [10]. Although most cases of unintentional arterial cannulation involve the radial artery branches of the forearm and hand, superficial ulnar arteries also have been reported to be involved in $2 \%$ to $3 \%$ of patients [10] and 12 variations of the superficial palmar arch and 7 variations of the deep palmar arch have been described [1]. In our case while giving the test dose of Benzyl penicillin, accidental injury to the wall of ulnar artery or its branch or an abnormal/aberrant superficial branch of ulnar artery might have taken place as all fingers except thumb were affected [1] [2].

Indicators of intra-arterial cannulation includes, the bright red backflow of blood into the IV catheter/syringe and even pulsatile movement may be seen in the iv tubing [1] [10]. However these indicators are equivocal or subtle at best [1]. In our case there was no backflow which would have warned the staff.

The pathophysiological mechanism of peripheral gangrene after intra-arterial injection remains unclear [1] [3] [6] [10]. Many theories have been put forward like: 1) norepinephrine-mediated vasoconstriction; 2) mechanical blockage of microcirculation; 3) inflammation of endothelium; 4) thrombosis theory; 5) lipid solubility theory; 6) crystal theory; 7) direct cytotoxicity theory etc. [1] [10]. All concepts agree with the mechanism of peripheral under perfusion due to endarteritis, vasospasm [1] [5] [6] and thrombosis leading to the tissue necrosis [1] [2] [10]. In our case it is assumed that prolonged vasospasm of the vessel of forearm was a major cause and crystal of drug might have occlude the lumen for short time as color dopler flow study and arteriography didn't reveal any pathological changes in the involved vessels. It is suspected that some micro emboli may have resulted in occlusion of the end artery of interdigital vessels of distal phalanx of the little finger that might have resulted in gangrene of the tip of distal phalanx of the little finger. Thrombotic changes was not detected as patient was already on anticoagulants (Tab Nicunalome), Tab Acetylsalicylic acid (antiplatelets) and spasm was releaved by effect of vasodilators (Tab clopidrogel).

In iatrogenic intra-arterial injection pain is often the initial symptom [1]-[3] [10]. Other signs and symptoms are pallor, pulselessness, tingling, numbness, cyanosis, paresis of muscles of the involved part, oedema of the limb, necrosis, gangrene and permanent function deficit may occur as a complication [1] [10]. Most of the above complications occurred in our patient also.

With prompt intervention, the morbidity resulting from intra-arterial injection can be prevented [1] [2]. Various treatment options have been proposed that include 1) immediate elevation of extremity to heart level; 2) immediate and adequate Heparinisation; 3) sympathetic block; 4) narcotic analgesic to control pain; 5) reversal of spasm; 6) maintaining and /or re-establishing blood flow to the distal portion of extremity; 7) thrombectomy to establish pulses in major vessels where needed; 8) treating any sequeale of vascular ischemia (oedema, compartment syndrome, gangrene and rehabilitation [1] [2] [10]; 9) surgical treatment of gangrenous areas with amputation of large areas of tissue necrosis [1] [6].

Our patient presented herein has responded well to conservative therapy with drugs like, 1) Tab Nicunalome 3 mg (anticoagulants); 2) Tab Acetylsalicylic acid (antiplatelet); and 3) Tab Tramadol hydrochloride 50 mg (pain killer) and Heparinisation with Injection Deltaparin 5000 IU S/c for 5 days without much sequeale. Reason for lesser morbidity in our patient was prompt diagnosis and immediate intervention and moreover the patient was already taking above drugs for last one month.

\section{Conclusion}

Unintentional intra-arterial injection or arterial wall injury is associated with serious sequeale ranging from blanching, pain, paresis/paralysis, oedema, necrosis of tissue to gangrene and finally the amputation of the part. So education of the ancillary staff involved in the administration of injections is necessary. They should have thorough knowledge of the site and technique of administration of injection. They should have knowledge about the anatomy of the vessel as and their anomalies in the antecubital fossa and around the wrist area. They should be aware of drugs that may result in devastating consequences if given intra-arterially accidentally. From treatment point of view, immediate recognition of the situation, assessment of progress of disease, controlling the pain, administering the anticoagulants, care of the affected part, specific therapy and rehabilitation is necessary. 
Such incidence can be prevented if a medically trained physician directly supervises the junior staff/nursing students or other paramedical persons involved in IV drug administration.

\section{References}

[1] Sen, S., Chin, E.N. and Brown, M.J. (2005) Complications after Unintentional Intra-Arterial Injection of Drugs: Risks, Outcomes, and Management Strategies. Mayo Clinic Proceedings, 80, 783-795. http://dx.doi.org/10.1016/S0025-6196(11)61533-4

[2] Iblher, N., Stark, G.B. and Penna, V. (2011) Necrosis of the $4^{\text {th }}$ and $5^{\text {th }}$ Digits after Intra-Articular Injection of Diazepam into the Wrist. Case Reports in Surgery, 2011, Article ID: 347523. http://dx.doi.org/10.1155/2011/347523

[3] Kumar, M., Singh, J., Sharma, P., Khera, A. and Singh, P. (2015) Accidental Intra-Arterial Injection of Diclofenac Sodium-Case Report. Journal of Clinical and Diagnostic Research, 9, PD16-PD17.

[4] Engler, H.S., Purvis, J.G., Kanavage, C.B., Ogden, L.L., Freeman, R.A. and Moretz, W.H. (1967) Gangrenous Extremities Resulting from Intra-Arterial Injection. Archives of Surgery, 94, 644-651. http://dx.doi.org/10.1001/archsurg.1967.01330110060008

[5] Sengupta, S. (1976) Gangrene Following Intra-Arterial Injection of Procaine Penicillin. Australian New Zealand Journal of Medicine, 6, 71-73. http://dx.doi.org/10.1111/j.1445-5994.1976.tb03295.x

[6] Goldsmith, D. and Trieger, N. (1975) Accidental Intra-Arterial Injection: A Med Emergency. Anesthesia Progress, 22, 180-183.

[7] Schanzer, H. and Jacobson 2nd, J.H. (1985) Tissue Necrosis Caused by Inta-Arterial Injection of Long Acting Penicillin. Pediatrics, 75, 741-744.

[8] Wynne, J.M., Williams, G.L. and Ellman, B.A.H. (1978) Accidental Intra-Arterial Injection. Archives of Disease in Childhood, 53, 396-400. http://dx.doi.org/10.1136/adc.53.5.396

[9] Joist, A., Tibesku, C.O., Neuber, M., Frerichmann, U. and Joosten, U. (1999) Gangrene of Fingers Caused by Accidental Intra-Arterial Injection of Diazepam. Deutsche Medizinische Wochenschrift, 124, 755-758. http://dx.doi.org/10.1055/s-2007-1024408

[10] Dasgupta, M., Adhikari, S. and Datta, M. (2012) Inadvertent Intra-Arterial Injection Leading to Gangrene: A Rare but Devastating Postoperative Complication. Journal of Obstetrics Gynaecology of India, 62, 56-58. http://dx.doi.org/10.1007/s13224-013-0359-5

[11] Goldberg, I., Bahar, A. and Yosipovitch, Z. (1984) Gangrene of Upper Extremitiy Following Intra-Arterial Injection of Drugs. A Case Report and Review of Literature. Clinical Orthopaedics and Related Research, 188, 223-229. 